\title{
ALLOGENEIC STEM CELL TRANSPLANTATION TO CURE HEMATOLOGICAL MALIGNANCIES
}

\author{
Nicolaus Kröger
}

University Medical Center Hamburg-Eppendorf, Department of Stem Cell Transplantation, Hamburg, Germany

Correspondence: nkroeger@uke.uni-hamburg.de

After the Second World War many efforts in research were spent to investigate how to repair radiation effects resulting from the observation of radiation damage post-atomic bomb explosions among survivors in Japan in World War II. In the late 1940s in preclinical animal models protection from total body irradiation (TBI) by shielding the spleen in mice were discovered as well as radiation protection by infusing marrow cells. Thus, in the beginning it was thougt that humoral factors in spleen or marrow might be the cause of protection. But later on it could be convincingly shown that protection was due to marrow cells. This led to great enthusiasm to perform high-dose chemo- or radiation therapy and salvage the destroyed marrow by donor bone marrow graft. At this point there was no knowledge about histocompatibility and graft rejection and in those who had transient engraftment a so called graft-versus-host disease was observed. So, the first human marrow grafts were reported between 1957 and 1967. But all 200 patients died from complications such as graft failure, graft-versus-host disease, infections or recurrenc of leukemia and the field of hematopoietic stem cell transplantation was declared as dead in the 1960s.

But fortunately research went back to the laboratory focused on animal studies to get more insight and knowledge about the biology of allogeneic stem cell transplantation. In the following years groups in the Netherlands and the US developed improved conditioning regimen such as cyclophosphamide including antithymocyte globulin or busulfan as myeloablative immunosuppressive therapy, developed the histocompatibility system in dogs which allows a better matching between donor-recipient pairs, and using drugs such as methotrexate to prevent post-transplant graft-versus-host disease.
Thus, researchers and clinicians went back to patients and first successful transplantation was then performed mainly in primary immunosufficiencies, Wiskott-Aldrich syndrome or aplastic anemia. Others focussed on late stage leukemias, results in GVHD prophylaxis and treatment improvement by the introduction of calcineurin inhibitors such as cyclosporine A or tacrolimus and also by defining HLAidentical sibling as stem cell source.

First clinical studies could show clear correlation between occurrence of graft-versus-host disease and risk of relapse and firmly established the existence of graft-versus-leukemia effect induced by donor T-cells which later led to the application of donor lymphocyte infusion after stem cell transplantation in patients who relapsed.

The field developed rapidly and in the late 1980s the introduction of G-CSF mobilized peripheral blood stem cells as stem cell source led to a faster engraftment. Since only one-third of the patients has an HLA-identical sibling transplantation alternative donor sources were explored. Several unrelated donor registries were established resulting now in an unrelated donor pool of about 30 million people around the world.

Other alternative donor sources such as cord blood and haploidentical stem cell transplantation first as strong T-cell depletion with CD34 selected cells, later with the use of post-transplant cyclophosphamide have further increased the number of stem cell transplantations around the world.

Nevertheless non-relapse mortality caused by infections, graft-versus-host disease or toxicity induced by the conditioning regimen remains a major problem. Numerous preclinical and clinical research was done to reduce toxicity of the conditioning regimen by using so called reduced 
intensity conditioning regimen or non-myeloablative conditioning regimen with low-dose TBI as well as the development of new forms of GVHD prophylaxis by including also mTOR inhibitors and other forms of T-cell depletion such as alemtuzumab or ATG.

All these efforts resulted in a significant reduction of non-relapse mortality could be achieved while the other reason for treatment failure which is relapse remains pretty stable over the last forty years. Therefore the ongoing clinical research in stem cell transplantation is mainly focused on reducing the risk of relapse by developing strategies to monitor minimal residual disease by including novel agents pre- and post-transplantation and consider allogeneic stem cell transplantation not any more as ultima ratio for hematological malignancies rather than as a part of a strategy including chemo-, immuno- or molecular-based therapies in order to cure more patients with hematological malignancies.
Additional efforts were made to separate the graft-versus-host and graft-versus-leukemia effect by trying to select the proper donor T-cells or by manipulating the donor T-cell with the aim to target mainly tumor-specific antigens. In this context during the last years the manipulation of T-cells genetically to target the corresponding tumor more specifically the CAR-T-cell field is exploding and first CAR-T-cell products are commercially available.

Nowadays about 20,000 allogeneic stem cell procedures are performed within Europe annually and the numbers are increasing. Main indications are myeloid leukemia, acute lymphblastic leukemia, myeloid malignancies such as MDS or myeloproliferative disorders. Allogeneic stem cell transplantation, immunotherapy, and cellular therapies remain an exciting curative treatment for many hematological diseases and reducing the risk of relapse and non-relapse mortality will further increase of the cure rate in the next years.

\section{Recommended literature}

Bekkum DW van, De Vries MJ. Radiation chimeras. New York: Academic Press; 1967.

Bortin MM. A compendium of reported human bone marrow transplants. Transplantation. 1970;9:571-587.

Gluckman E, Broxmeyer HE, Auerbach AD, et al. Hematopoietic reconstitution in a patient with Fan-coni's anemia by means of umbilical-cord blood from HLAidentical sibling. N Engl J Med. 1989;321:1174-1178.

Gratwohl A, Pasquini MC, Aljurf M, Worldwide Network for Blood and Marrow Transplantation (WBMT), et al. One million hematopoietic stem-cell transplants: a retrospective observational study. Lancet Haematol. 2015a;2:e91-100.

Kolb HJ, Mittermüller J, Clemm C, et al. Donor leukocyte transfusions for treatment of recurrent chronicmyelogenous leukemia in marrow transplant patients. Blood. 1990;76:2462-2465.

Luznik L, O'Donnell PV, Symons HJ, et al. HLAhaploidentical bone marrow transplantation for hematologic malignancies using nonmyeloablative conditioning and high-dose, post-transplantation cyclophosphamide. Biol Blood Marrow Transplant. 2008;14:641-650.

Mathé G, Jammet H, Pendic B, et al. Transfusions and grafts of homologous bone marrow in humans after accidental high dosage irradiation. Rev Fr Etud Clin Biol. 1959;4:226-238.

Thomas ED, Storb R, Clift RA, et al. Bone-marrow transplantation. N Engl J Med. 1975;292:832-843.895-902.

Weiden PL, Flournoy N, Thomas ED, et al. Antileukemic effect of graft-versus-host disease in human recipients of allogeneic-marrow graft. N Engl J Med. 1979;300:1068-1073. 